\title{
Obesity in South Africa: The South African Demographic and Health Survey
}

\author{
Thandi Puoane, *† Krisela Steyn, * Debbie Bradshaw, $\neq$ Ria Laubscher, § Jean Fourie, * Vicki Lambert, $\|$ \\ and Nolwazi Mbanangał:
}

\begin{abstract}
PUOANE, THANDI, KRISELA STEYN, DEBBIE BRADSHAW, RIA LAUBSCHER, JEAN FOURIE, VICKI LAMBERT, AND NOLWAZI MBANANGA. Obesity in South Africa: The South African Demographic and Health Survey. Obes Res. 2002;10:1038-1048.

Objectives: To ascertain the anthropometric profile and determinants of obesity in South Africans who participated in the Demographic and Health Survey in 1998.

Research Methods and Procedures: A sample of 13,089 men and women (age, $\geq 15$ years) were randomly selected and then stratified by province and urban and nonurban areas. Height, weight, mid-upper arm circumference, and waist and hip circumference were measured. Body mass index (BMI) was used as an indicator of obesity, and the waist/hip ratio (WHR) was used as an indicator of abdominal obesity. Multivariate regression identified sociodemographic predictors of BMI and waist circumference in the data.
\end{abstract}

Results: Mean BMI values for men and women were 22.9 $\mathrm{kg} / \mathrm{m}^{2}$ and $27.1 \mathrm{~kg} / \mathrm{m}^{2}$, respectively. For men, $29.2 \%$ were overweight or obese $\left(\geq 25 \mathrm{~kg} / \mathrm{m}^{2}\right)$ and $9.2 \%$ had abdominal obesity (WHR $\geq 1.0$ ), whereas $56.6 \%$ of women were overweight or obese and $42 \%$ had abdominal obesity (WHR $>0.85$ ). Underweight (BMI $<18.5 \mathrm{~kg} / \mathrm{m}^{2}$ ) was found in $12.2 \%$ of men and $5.6 \%$ of women. For men, $19 \%$ of the variation of BMI and $34 \%$ of the variation in waist circumference could be explained by age, level of education, population group, and area of residence. For women, these variables explained $16 \%$ of the variation of BMI and $24 \%$ of

Received for review January 1, 2002.

Accepted for publication in final form July 3, 2002.

*Chronic Diseases of Lifestyle Unit of the Medical Research Council (MRC), $\dagger$ Burden of Disease Research Unit of the MRC, and $¥$ Biostatistics Unit of the MRC, Tygerberg, South Africa and §Sports Sciences Institute, Department of Physiology, University of Cape Town, Newlands, South Africa.

† Present address/address correspondence: Dr. Thandi Puoane, School of Public Health, University of the Western Cape, Private Bag X17, Bellville 7535, South Africa.

E-mail: tpuoane@uwc.ac.za

Copyright $\odot 2002$ NAASO the variation in waist circumference. Obesity increased with age, and higher levels of obesity were found in urban African women.

Discussion: Overnutrition is prevalent among adult South Africans, particularly women. Determinants of overnutrition include age, level of education, ethnicity, and area of residence.

Key words: body mass index, waist-to-hip ratio, developing countries, overweight

\section{Introduction}

In developing countries undergoing health or epidemiological transition, a complex picture relating to nutritional status of the population is frequently found (1). In these communities, a malnutrition pattern is predominantly characterized by undernutrition in children, whereas in adults, ever-increasing obesity is found (2). In 1997, the World Health Organization emphasized that obesity is becoming a major health problem in many developing countries, particularly in adult women (3). This presents a significant threat to the emergence of noncommunicable diseases in the developing world as suggested by Reddy et al. (4). Obesity is associated with increasing risk of developing hypertension (5-7), coronary heart diseases (8-10), diabetes $(11,12)$, stroke, and some forms of cancer $(13,14)$ in both African and white populations.

In the past, data on the nutritional status and dietary intake patterns in the African community (the majority of the South Africans with high poverty levels) were collected in a number of regional studies (15-18). The more urbanized these African communities were, the higher the rate of obesity and the less prudent their diets became $(6,10,15,18)$. The anthropometric trends of extreme overnutrition suggested by these smaller studies and the dearth of national data on the anthropometric patterns in adult South Africans motivated the inclusion of these measurements in a representative sample such as this study. This article reports anthropometric data and sociodemographic determinants of 
obesity collected in 1998 in South Africa's first National Demographic and Health Survey (SADHS).

\section{Research Methods and Procedures}

The SADHS is a national cross-sectional study. Twostage sampling was employed to select a representative sample, using the 1996 census demarcation as a sampling frame (19). The sample was stratified into the nine provinces and by urban and nonurban areas. The first stage consisted of selecting census enumeration areas (EA) with probability proportional to the size, based on the number of households residing in the EA within each stratum. Secondly, a systematic sample of households was identified in each selected EA with a cluster of 10 households in the nonurban and 5 in the urban areas. Oversampling in some provinces was done to ensure estimates for men and women in each of the nine provinces and for ethnic groups based on the individual's self-classification. Sampling without replacement was used and up to three visits were undertaken to interview the selected respondents.

Respondents were men and women $\geq 15$ years of age. Pregnant women and people who could not stand up straight, or those in wheelchairs were excluded from the study.

The fieldwork took place between January and September of 1998. An adult health questionnaire was used to collect information on lifestyle habits that influence health and commonly occurring chronic adult diseases. Included in the adult health questionnaire, was a question on perceptions regarding body weight. The questionnaire was developed in English, and then translated into each of the eleven official languages spoken in South Africa. Field workers received intensive training on how to conduct the interview and how to take the following anthropometric measurements: height, weight, mid-upper arm circumference (MUAC), and waist and hip circumferences.

Weight was measured to the nearest $0.5 \mathrm{~kg}$ using a calibrated bathroom scale manufactured by Soehnle (Nassau, Germany). Each subject was weighed wearing light clothing without shoes or stockings. Height was measured using a metal measuring tape, secured against a flat wall and a flat headboard placed at right angles to the wall to ensure correct reading. Where a wall was not available, the nearest flat upright surface was used. Each respondent was requested to stand barefoot, with the back and legs straight and the back of the head placed against the wall. The head was positioned in such a way that the angle of the eye and the opening of the external auditory meatus were on a horizontal line. Height was measured to the nearest $0.1 \mathrm{~cm}$. A flexible tape measure was used to take the measurements of body circumferences.

The MUAC was measured on the left arm halfway between the acromion process of the humerus and the olecranon process of the ulna, with the arm relaxed alongside the body. Measurements were taken to the nearest $0.1 \mathrm{~cm}$. The smallest circumference between the xiphi sternum and the umbilicus on expiration was taken as the waist circumference. Measurements were taken to the nearest $0.1 \mathrm{~cm}$ after normal expiration while in an upright position. Hip circumference was measured to the nearest $0.1 \mathrm{~cm}$ at the maximum posterior protuberance of the buttocks while the participant was standing upright with feet together.

\section{Statistical Analysis}

The anthropometric indices computed were as follows: body mass index (BMI) as weight in kilograms divided by height in meters squared; underweight was defined as BMI $<18.5 \mathrm{~kg} / \mathrm{m}^{2}$; overweight was defined as BMI 25 to 29.9 $\mathrm{kg} / \mathrm{m}^{2}$; and obesity was defined as BMI $\geq 30 \mathrm{~kg} / \mathrm{m}^{2}$ for all subjects (3). The cutoff point for central obesity was a waist circumference $\geq 102 \mathrm{~cm}$ for men and $\geq 88 \mathrm{~cm}$ for women (3).

The WHR was computed as the waist circumference divided by hip circumference. Gender-specific cutoff points of $\geq 1.0$ and $\geq 0.85$ were used to define abdominal obesity for men and women, respectively (3). BMI categories with "apple" and "pear" shapes based on WHR cutoffs were considered. A MUAC of $23 \mathrm{~cm}$ was used to identify adults who were undernourished, and a MUAC of $\geq 33 \mathrm{~cm}$ for those who were obese (3).

The Taylor expansion theory for estimating the sampling error of estimators was used. Nationally representative estimates are calculated using weights for each urban or rural stratum of each province based on the sample size and the response rate. Age-standardized proportions were calculated using the World age distribution as standard (20).

Regression analysis, using Proc Surveyreg in SAS Version 8 (SAS Institute; Cary, NC), was performed for men and women separately, with BMI and waist circumference as continuous dependent variables. This procedure is appropriate for complex survey sample designs, including designs with stratification, clustering, and unequal weighting. In addition to the SE, the design effect for each estimate, which is defined as the ratio of the variance of complex sampling to the variance computed under the assumption of simple random sampling. A parsimonious fit was identified to give an optimal correlation coefficient $\left(R^{2}\right)$.

The following cutoff points and aggregations were selected (reference groups indicated in bold): age (women) 15 to 24 years, 25 to 34 years, 35 to 44 years, 45 to 54 years, 55 to 64 years, $\geq 65$ years; age (men) 15 to 24 years, 25 to 34 years, 35 to 44 years, $\geq 45$ years; education: no education, primary school (grades 1 to 7 ), secondary school (grades 8 to 12), and tertiary education; geographic setting: nonurban and urban setting; population group (self-classification): Indian, mixed ancestry, white, and African.

Race-based population groups were defined by Apartheid. Africans were those whose ancestry is from the Afri- 
Table 1. South-African adults $\geq 15$ years of age participating in the Demographic and Health Survey

\begin{tabular}{|c|c|c|c|c|c|c|}
\hline \multirow{2}{*}{$\begin{array}{l}\text { Background } \\
\text { characteristic }\end{array}$} & \multicolumn{2}{|c|}{ Men } & \multicolumn{2}{|c|}{ Women } & \multicolumn{2}{|c|}{ Total } \\
\hline & $n$ & $\%$ & $n$ & $\%$ & $n$ & $\%$ \\
\hline \multicolumn{7}{|l|}{ Age } \\
\hline 15 to 24 & 1772 & 32.8 & 2016 & 26.0 & 3788 & 28.9 \\
\hline 25 to 34 & 1030 & 19.0 & 1563 & 20.2 & 2593 & 19.8 \\
\hline 35 to 44 & 948 & 17.6 & 1345 & 17.4 & 2293 & 17.5 \\
\hline 45 to 54 & 649 & 12.0 & 1039 & 13.5 & 1688 & 12.9 \\
\hline 55 to 64 & 495 & 9.2 & 905 & 11.7 & 1400 & 10.7 \\
\hline 65 to 95 & 507 & 9.4 & 858 & 11.1 & 1365 & 10.4 \\
\hline \multicolumn{7}{|l|}{ Residence } \\
\hline Urban & 3116 & 57.7 & 4243 & 54.9 & 7359 & 56.1 \\
\hline Nonurban & 2285 & 42.3 & 3483 & 45.1 & 5768 & 43.9 \\
\hline \multicolumn{7}{|l|}{ Education } \\
\hline No education & 615 & 11.4 & 1227 & 15.9 & 1842 & 14.0 \\
\hline Grades 1 to 5 & 759 & 14.1 & 1092 & 14.1 & 1851 & 14.1 \\
\hline Grades 6 to 7 & 787 & 14.6 & 1158 & 15.0 & 1945 & 14.8 \\
\hline Grades 8 to 11 & 2134 & 39.5 & 2870 & 37.1 & 5004 & 38.1 \\
\hline Grade 12 & 702 & 13.0 & 913 & 11.8 & 1615 & 12.3 \\
\hline Tertiary education & 376 & 6.7 & 435 & 5.6 & 811 & 6.2 \\
\hline Not reported & 16 & 0.3 & 11 & 0.1 & 27 & 0.2 \\
\hline \multicolumn{7}{|l|}{ Population group } \\
\hline African & 4006 & 74.2 & 5897 & 76.3 & 9903 & 75.4 \\
\hline African, urban & 1995 & 36.9 & 2735 & 35.4 & 4730 & 36.0 \\
\hline African, nonurban & 2011 & 37.2 & 3162 & 40.9 & 5173 & 39.4 \\
\hline Mixed & 740 & 13.7 & 986 & 12.8 & 1726 & 13.1 \\
\hline White & 470 & 8.7 & 572 & 7.4 & 1042 & 7.9 \\
\hline Asian & 174 & 3.2 & 262 & 3.4 & 436 & 3.3 \\
\hline Total & 5401 & 41.1 & 7726 & 58.9 & 13127 & 100 \\
\hline
\end{tabular}

can continent; whites were those with European ancestry; the mixed-ancestry group (a uniquely defined South-African group) was of mixed heritage, including aboriginal (Koi, San), Malay, European, and African; and Indian/Asian defines those descendants from East Asia, primarily the Indian subcontinent. The South-African population is made up of $77 \%$ African, $11 \%$ white, $9 \%$ mixed ancestry, and 3\% Indian/Asian. Fifty-four percent lived in urban areas according to the 1996 Census (19). The white and Indian/Asian South Africans are largely urbanized, whereas the Africans have a larger rural base. Less than a third of the mixedancestry South Africans live in rural areas. Socioeconomic status, and consequently health, is associated with population grouping as a result of the systematic exploitation of Apartheid.

The Ethics Committee of the South African Medical Research Council approved this research protocol, and all participants gave informed verbal consent.

\section{Results}

Of 14,298 eligible adults identified, 13,827 participated in the study, giving an overall response rate of $89.7 \%$. Anthropometric measurements were not taken for 172 respondents, measurements were not taken from another 215 , and 313 respondents were excluded from the analysis after analyzing the data. The data were analyzed by regression analysis for men and women separately, to predict BMI on MUAC and waist measurements. Only those individuals for whom the BMI values fell within the $99 \%$ confidence interval of the predicted values, as well as those who fell within the range of 12 to $60 \mathrm{~kg} / \mathrm{m}^{2}$ were included in the analysis. The demographic characteristics of the study population are shown in Table 1 . The oldest respondents in the sample were 95 years. Approximately $56 \%$ of the respondents were urban residents, and $44 \%$ lived in rural areas. African respondents 
comprised $75.4 \%$, followed by the mixed-ancestry group $(13.1 \%)$, whites $(7.9 \%)$, and $3.3 \%$ Indian respondents.

Table 2 presents gender-specific means and SEs of seven anthropometric variables. The following trends were observed: in general, men were $10 \mathrm{~cm}$ taller than women. The differences were constant across the age range except for the $\geq 65$-year age group, in which the differences between men and women were even more marked. Although men were taller than women, the mean weight in women was greater than that of men (mean difference, $2.1 \mathrm{~kg}$ ). The heaviest women fell into the 35-to-64-year-old age group. BMI in women continued to rise until age 64 years and then declined thereafter. In men, BMI increased with age until 45 years and then remained more or less constant below that of the women.

The mean level of MUAC was higher for women than for men. The pattern of MUAC levels paralleled that found for the obesity patterns reported above. Also shown in Table 2, for men and women, are their mean waist and hip circumferences and WHR. The mean waist circumference in women increased with age until 64 years and declined thereafter. In men, the waist circumference increased with age but remained constant after 55 years. Men and women had equal levels of waist-hip ratio, except men $\geq 45$ years of age, who had slightly higher values.

In Table 3 the percentage distribution of the BMI categories of underweight, normal weight, overweight, and obese is shown for men and women in the different population groups. Underweight occurred rarely in South-African adults; however, it was much higher in men (12.2\%) than in women (5.6\%), and the highest among Indian men and women (16.9\% and $14.9 \%$, respectively). In fact, underweight was rare in women. Underweight was reported among $10.8 \%$ of urban and $16.4 \%$ of nonurban men; and it was reported among $5.0 \%$ of urban and $6.5 \%$ of nonurban women. In contrast, $29.2 \%$ of men and $56.6 \%$ of women with very high rates of overweight and obesity were classified in these two categories. More women than men fell above the cutoff values for MUAC, waist circumference, and WHR.

Central obesity was found in $42.2 \%$ of women and $9.2 \%$ of men. Abdominal (apple-shaped) obesity was found in white men and in urban African and mixed-ancestry women, whereas African men were found to be more pearshaped than other ethnic groups. Interestingly, there are more apple-shaped African and mixed-ancestry women with normal weights compared with Indian and white women, whereas normal-weight men are more pear-shaped in all the population groups. The highest educated women had the smallest waist followed by those women with no education. Rural women had significantly larger waists, whereas Indian and white women had significantly smaller waists than Africans.
Data in Table 4 of the participants' perception about their own body weight allow a comparison with those actually found (see Table 3). In comparing the self-reported weight category of all participants with actually measured underweight and overweight/obesity (determined by BMI) it is clear that more people thought they were underweight ( $18.5 \%$ of men and $16.4 \%$ of women) than those who were found to be so (12.2\% of men and 5.6\% of women). Actual overweight/obesity was also completely underestimated. For example, $9.7 \%$ and $22.1 \%$ of men and women, respectively, perceived themselves as overweight, whereas $29.2 \%$ men and $56.6 \%$ women were indeed overweight or obese. These inaccurate perceptions of body weight were found to be different in the different population groups. Only white women's perceptions of overweight/obesity approximated the actual level of obesity found. This incorrect perception of body weight also related to the participant's level of education, with the least-educated groups for men and women showing the greatest discrepancies between perceived and actual categories of BMI (data not shown).

Tables 5 and 6 show the results of multivariate regression analysis that identified the following independent predictors of increasing BMI and waist circumference for men and women separately: for men, $19 \%$ of the variation of BMI could be explained by age, level of education, population group, and living either in a rural or urban setting; whereas for women, these demographic variables accounted for $34 \%$. Significantly higher levels of BMI were found in older men, those living in the city, and white men. Men with more than 8 years of schooling had a significantly higher BMI than those with less or no schooling.

In women, those who were older had significantly higher BMI levels than younger women, as did urban women compared with nonurban women and African women, who had significantly higher BMI than all the other groups. An interesting significant relationship was found among those women who had no education and those with more than 12 years of education having the highest BMI compared with those who had between 1 and 12 years of education.

The design effect for BMI ranged from 1.12 to 2.65, showing a degree of clustering in the data. It was generally smaller for women than men.

For men, $16 \%$ of the variation in waist circumference was explained by the demographic variables. Men who had significantly higher levels of abdominal obesity were older, had between 8 to 12 years of education, and lived in the city. In women, $24 \%$ of the variation in waist circumference could be explained by the demographic variables. The older women had significantly higher levels of abdominal obesity, and waist circumference increased significantly with age until 54 to 64 years and then decreased. Women with the highest level of education had significantly smaller waists than those with less education, but were not significantly different from those with no education. 


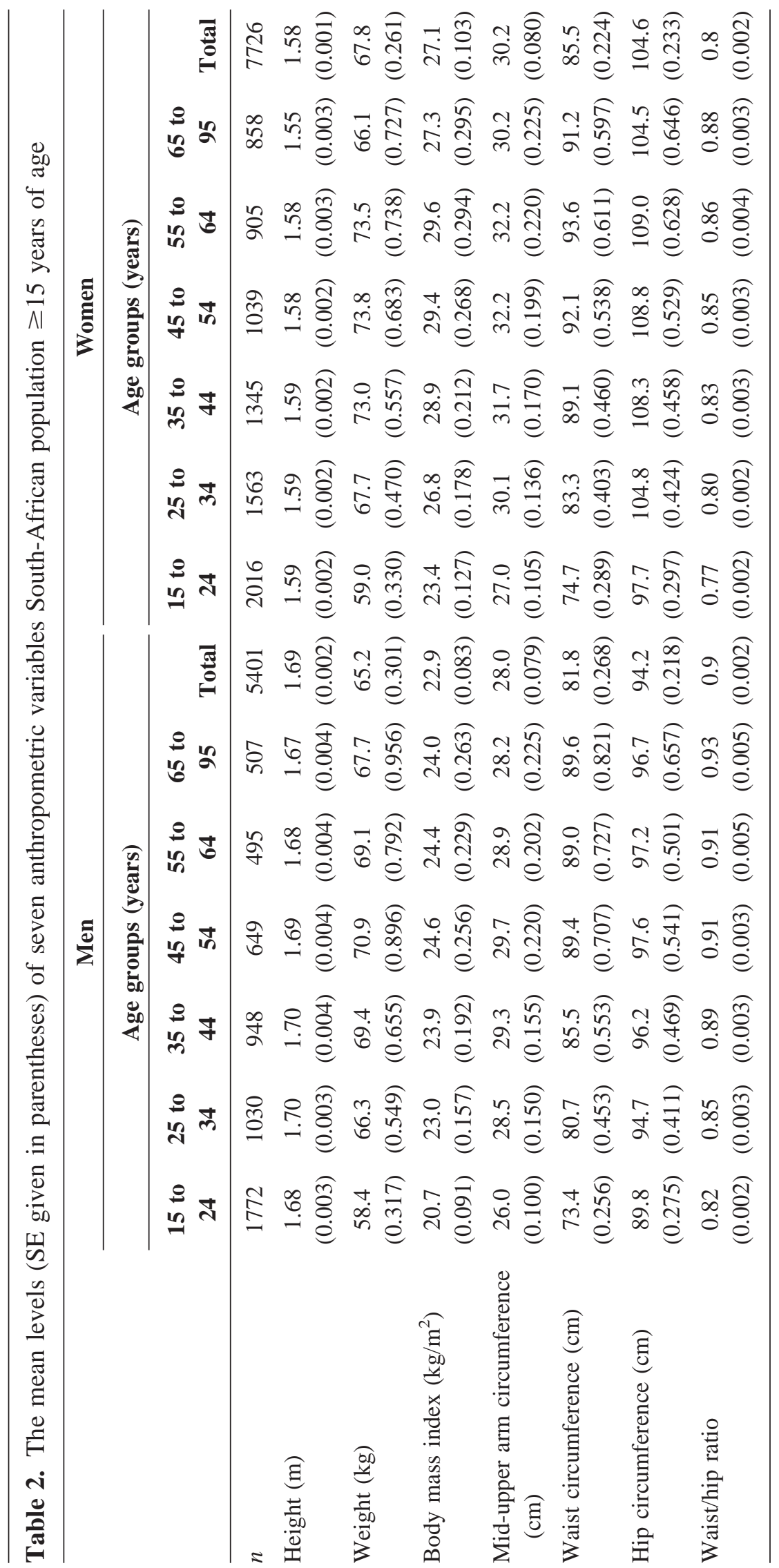




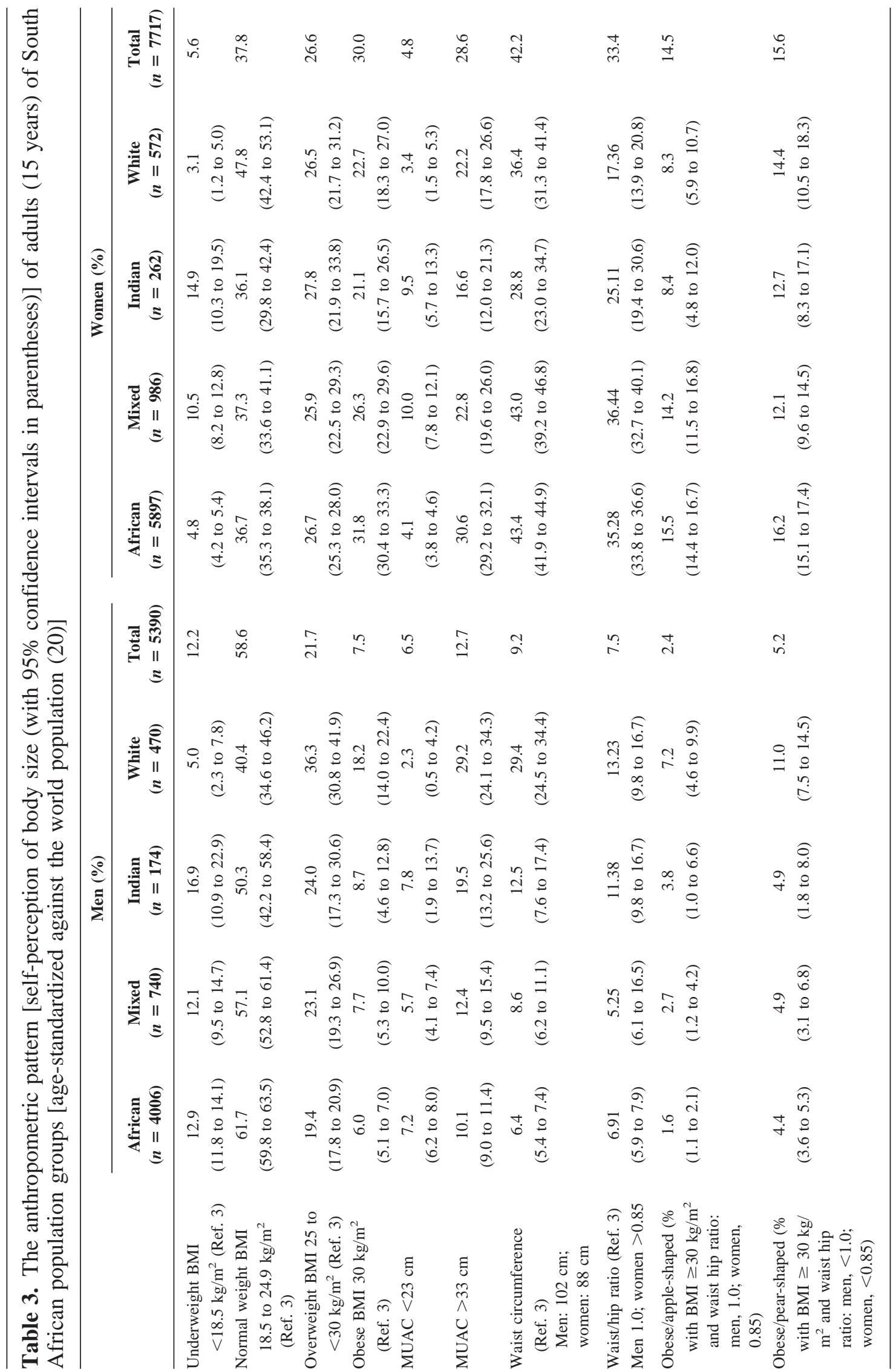




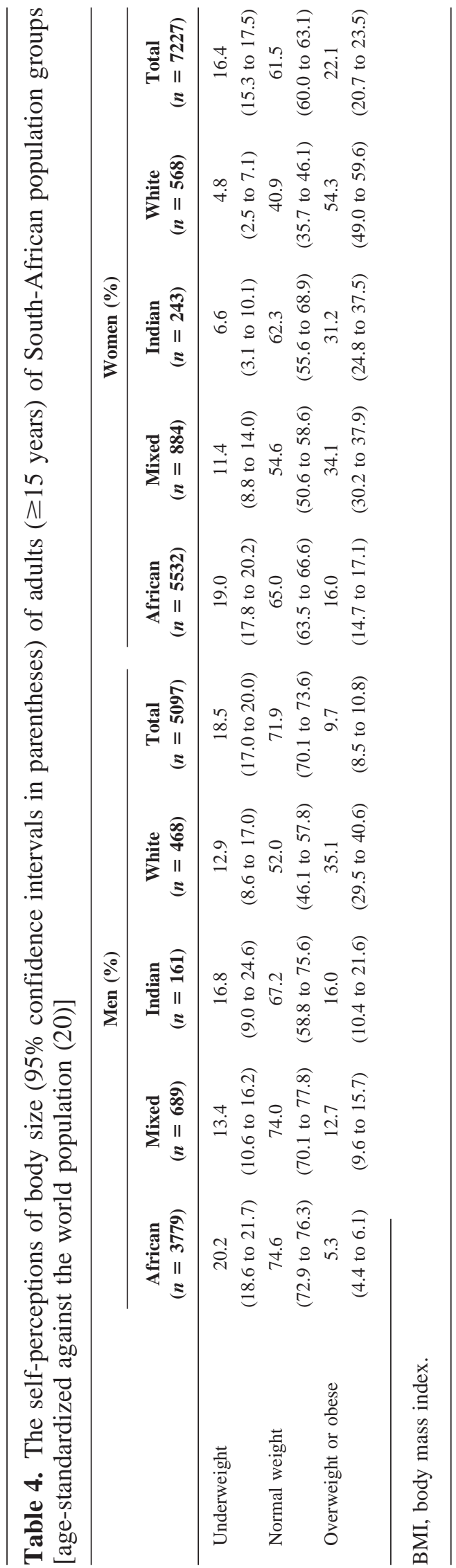

The design effect for waist measurements ranged from 1.23 to 3.56 , reflecting clustering in the data across all the sociodemographic factors included in the model.

\section{Discussion}

Earlier studies in the country on the anthropometric pattern of adults in South Africa covered a few small geographic areas and gave quite disparate patterns for the various population groups and regions of South Africa $(6,10,15,17,21)$. Estimates of the national anthropometric pattern and particular populations at risk were thus imprecise. The adult health section of the SADHS is the most geographically comprehensive, multiethnic measurement of the actual anthropometric pattern in South Africa. Similar studies conducted in Sub-Saharan Africa could not be found in the literature.

These data show an adult South-African population, with the malnutrition pattern one of predominantly overnutrition rather than undernutrition. Furthermore, there is an inaccurate perception of body weight by participants. This is a worrying situation because it has clearly been shown that obesity predisposes to hypertension (22) and diabetes in South-African populations (23). In addition, there is a trend toward higher levels of obesity in the urban setting compared with the nonurban setting, particularly for the African participants. Currently, there is an increasing rate of urbanization among the African population in South Africa that could impact on obesity and its sequelae in the future.

A further complexity to the possible prevention and management of obesity in Africans relates to their traditional and cultural perceptions concerning body size. Mvo et al. (24) has shown that being overweight has many positive connotations in the African community in South Africa. This qualitative research identified that being obese is perceived to reflect affluence and happiness in many sectors of the African population. This has also been confirmed in data recently collected by the authors in the urban township. Obesity or overweight in women is thought to reflect on a husband's ability to care for his wife and family. In addition, with the explosive increase in prevalence of African people with full-blown AIDS, obesity is seen to reflect persons who are healthy and without human immunodeficiency virus/AIDS (25). Unfortunately, questions to explore this belief were not included in this study and data on human immunodeficiency virus status was not collected.

The difference in self-perceived rates of obesity between African and white women is also of interest. Although the highest rates of obesity were reported among African women, fewer perceived themselves to be obese compared with perceptions reported by white women. Similar findings have been reported in the National Health Interview Survey in the US (26). Despite a higher overall prevalence of overweight, fewer African women considered themselves overweight compared with white women (26). 
Table 5. Demographic variables associated with increased body mass index and waist in adult South-African men identified by multivariate regression

\begin{tabular}{|c|c|c|c|c|c|c|c|c|}
\hline \multirow[b]{2}{*}{ Demographic variables } & \multicolumn{4}{|c|}{ BMI $\left(R^{2}=0.1945\right)$} & \multicolumn{4}{|c|}{ Waist $\left(R^{2}=0.3354\right)$} \\
\hline & $p$ model & Estimate & SE & $p$ estimate & $p$ model & Estimate & SE & $p$ estimate \\
\hline Intercept & $<0.0001$ & 25.794 & 0.337 & $<0.0001$ & $<0.0001$ & 92.145 & 0.900 & $<0.0001$ \\
\hline Age & $<0.0001$ & & & & $<0.0001$ & & & \\
\hline 15 to 24 Years & & -3.777 & 0.181 & $<0.0001$ & & -15.911 & 0.556 & $<0.0001$ \\
\hline 25 to 34 Years & & -1.676 & 0.213 & $<0.0001$ & & -9.082 & 0.602 & $<0.0001$ \\
\hline 35 to 44 Years & & -0.609 & 0.225 & 0.0069 & & -4.014 & 0.661 & $<0.0001$ \\
\hline$\geq 45$ Years & & 0.000 & 0.000 & & & 0.000 & 0.000 & \\
\hline Education & $<0.0001$ & & & & $<0.0001$ & & & \\
\hline No education & & -2.148 & 0.367 & $<0.0001$ & & -6.582 & 1.013 & $<0.0001$ \\
\hline 1 to 7 Years & & -1.880 & 0.313 & $<0.0001$ & & -5.208 & 0.846 & $<0.0001$ \\
\hline 8 to 12 Years & & -0.996 & 0.299 & 0.0009 & & -2.769 & 0.796 & 0.0005 \\
\hline$>12$ Years & & 0.000 & 0.000 & & & 0.000 & 0.000 & \\
\hline Geographic setting & $<0.0001$ & & & & 0.0330 & & & \\
\hline Urban & & 0.000 & 0.000 & & & 0.000 & 0.000 & \\
\hline Nonurban & & -0.590 & 0.150 & $<0.0001$ & & -1.005 & 0.471 & 0.0330 \\
\hline Population group & $<0.0001$ & & & & $<0.0001$ & & & \\
\hline Indian & & -0.375 & 0.414 & 0.3649 & & 2.987 & 1.073 & 0.0055 \\
\hline Mixed & & 0.357 & 0.232 & 0.1252 & & 1.716 & 0.658 & 0.0093 \\
\hline White & & 2.249 & 0.323 & $<0.0001$ & & 10.398 & 1.045 & $<0.0001$ \\
\hline African & & 0.000 & 0.000 & & & 0.000 & 0.000 & \\
\hline
\end{tabular}

BMI, body mass index.

Additional factors that could explain the high obesity rates in adult South Africans include changes in nutritional patterns over time and the degree of urbanization that Africans are undergoing. In 1940, Fox (27) found that the African population consumed a typical traditional diet, where the fat intake was only $16 \%$ of the total calories. By 1990, the fat intake in an urban African community had increased to $26 \%$ (17). When these data were analyzed further, it was shown that those people who had lived in cities for most of their lives already consumed a typical Westernized diet with $30 \%$ of calories from total fat, whereas those who had spent $<20 \%$ of their lives in the city only consumed $22.5 \%$ of calories from total fat (28). The possible explanation of these findings are prevailing conditions in industrialized societies, including availability and low cost of unhealthy food, and the use of labor-saving mechanical devices, which have greatly influenced excess calorie intake and decreased energy expenditure. Similarly, data from the US have shown that obesity is associated with availability of fast food, passive entertainment, such as watching television, and less physical activity in urban settings (29).
Our findings support those of Sundquist and Johansson (30), who investigated the influence of socioeconomic status, ethnicity, and lifestyle on BMI. They found a direct relationship between male socioeconomic status, defined by educational status and BMI, whereas in women only low educational levels were associated with a higher BMI.

Abdominal obesity was the highest in white urban and nonurban African women. This type of obesity has been shown to have more adverse health consequences than peripheral obesity $(31,20)$. Individuals with abdominal obesity are more likely to develop hypertension, diabetes mellitus, cardiovascular disease, and stroke. The highest rates of abdominal obesity were found in white men and in urban African and mixed-ancestry women. Abdominal obesity has previously been linked to diabetes and hypertension in regional prevalence studies in the African and mixedancestry communities of the Western Cape (22,23). Therefore, waist circumference and WHR may be important adult health indicators for ongoing surveillance.

In South Africa, obesity in women seems to start at a young age; these data show that $10 \%$ of women were obese 
Table 6. Demographic variables associated with increased body mass index and waist in adult South-African women identified by multivariate regression

\begin{tabular}{|c|c|c|c|c|c|c|c|c|}
\hline \multirow[b]{2}{*}{ Demographic variables } & \multicolumn{4}{|c|}{ BMI $\left(R^{2}=0.1597\right)$} & \multicolumn{4}{|c|}{ Waist $\left(R^{2}=0.2397\right)$} \\
\hline & $p$ model & Estimate & SE & $p$ estimate & $p$ model & Estimate & SE & $p$ estimate \\
\hline Intercept & $<0.0001$ & 28.037 & 0.467 & $<0.0001$ & $<0.0001$ & 89.878 & 0.975 & $<0.0001$ \\
\hline Age & $<0.0001$ & & & & $<0.0001$ & & & \\
\hline 15 to 24 Years & & -4.702 & 0.363 & $<0.0001$ & & -17.759 & 0.736 & $<0.0001$ \\
\hline 25 to 34 Years & & -1.222 & 0.346 & 0.0004 & & -8.529 & 0.744 & $<0.0001$ \\
\hline 35 to 44 Years & & 1.016 & 0.359 & 0.0047 & & -3.117 & 0.762 & $<0.0001$ \\
\hline 45 to 54 Years & & 1.783 & 0.368 & $<0.0001$ & & 0.332 & 0.760 & 0.6628 \\
\hline 55 to 64 Years & & 2.221 & 0.401 & $<0.0001$ & & 2.307 & 0.806 & 0.0043 \\
\hline$\geq 65$ Years & & 0.000 & 0.000 & & & 0.000 & 0.000 & \\
\hline Education & $<0.0001$ & & & & $<0.0001$ & & & \\
\hline No education & & -0.171 & 0.441 & 0.6978 & & 1.537 & 0.933 & 0.0999 \\
\hline 1 to 7 Years & & 0.981 & 0.377 & 0.0094 & & 4.318 & 0.803 & $<0.0001$ \\
\hline 8 to 12 Years & & 1.309 & 0.320 & $<0.0001$ & & 4.445 & 0.706 & $<0.0001$ \\
\hline$>12$ Years & & 0.000 & 0.000 & & & 0.000 & 0.000 & \\
\hline Geographic setting & $<0.0001$ & & & & $<0.0001$ & & & \\
\hline Urban & & 0.000 & 0.000 & & & 0.000 & 0.000 & \\
\hline Nonurban & & -1.602 & 0.202 & $<0.0001$ & & -2.265 & 0.429 & $<0.0001$ \\
\hline Population group & $<0.0001$ & & & & $<0.0001$ & & & \\
\hline Indian & & -3.259 & 0.437 & $<0.0001$ & & -6.998 & 0.986 & $<0.0001$ \\
\hline Mixed & & -1.683 & 0.340 & $<0.0001$ & & -1.382 & 0.724 & 0.0565 \\
\hline White & & -2.182 & 0.321 & $<0.0001$ & & -2.879 & 0.701 & $<0.0001$ \\
\hline African & & 0.000 & 0.000 & & & 0.000 & 0.000 & \\
\hline
\end{tabular}

BMI, body mass index.

at the ages 15 to 24 years. Therefore, primary prevention of obesity must start at a young age, particularly for girls. The multivariate regression analysis identified various groups who should be targeted for interventions for specific characteristics. In African women, the highest rate of obesity is predominantly in the urban women. The relationship between education and BMI is of interest because women with no education had lower BMIs than those with schooling. These women tend to do more manual labor than their better-educated counterparts. Women with tertiary education also had a lower BMI than those with some schooling. Two possible explanations could be considered. Firstly, this group of women are aware of the connection between body weight and health, secondly one could anticipate that this female group would take more cognizance of the preferred body image of thinness that reach them through the media. Consequently, they would try to control their body weight in an attempt to conform to the media images that they internalize. Obesity management is specifically required for older women in all the population groups.
The most important group to target for intervention among men is the urbanized, higher educated, and older white men, who have by far the highest rates of obesity among South-African men.

Table 7 provides a comparison of the rate of obesity from some African countries, migrant people of African descent and other South-African studies. In comparing the data from Ghana, Mali, and Tanzania with those from South Africa, we find it clear that these countries have much lower obesity rates than South Africa, whereas the rates reported for Mauritius fall more or less between these extremes. The African Americans had rates closer to those found in Africans from South Africa.

Overall, these data suggest that the predominant pattern of malnutrition in adult South Africans, particularly in African women, is one of overweight and remarkably high rates of abdominal obesity. The distribution of anthropometric variables in the South-African population differed by age, gender, education background, and area of residence. Therefore, suggesting that attention be directed toward in- 
Table 7. Obesity prevalence (body mass index $\geq 30 \mathrm{~kg} / \mathrm{m}^{2}$ ) in South Africa and selected countries in Africa and the US

\begin{tabular}{|c|c|c|c|c|}
\hline \multirow[b]{2}{*}{ Country (reference) } & \multirow[b]{2}{*}{ Year } & \multirow{2}{*}{$\begin{array}{c}\text { Ages } \\
\text { (years) }\end{array}$} & \multicolumn{2}{|c|}{$\begin{array}{c}\text { Prevalence of obesity } \\
(\%)\end{array}$} \\
\hline & & & Men & Women \\
\hline Ghana (3) & $1987 / 8$ & $\geq 20$ & & 0.9 \\
\hline Mali (3) & 1991 & $\geq 20$ & & 0.8 \\
\hline Mauritius (32) & 1992 & 25 to 74 & 5 & 15 \\
\hline USA (33) & 1988-94 & 20 to 74 & 19.9 & 24.9 \\
\hline Tanzania (34) & $1986 / 9$ & 35 to 64 & 0.6 & 3.6 \\
\hline \multicolumn{5}{|l|}{ South Africa } \\
\hline Cape Peninsula, Africans (15) & 1990 & 25 to 64 & 13.9 & 48.6 \\
\hline Mangaung, Africans (17) & 1990 & 25 to 64 & 12.9 & 43.9 \\
\hline QwaQwa, Africans (17) & 1990 & 25 to 64 & 12.7 & 40.2 \\
\hline Cape Peninsula, Mixed (6) & 1982 & 25 to 64 & 7.2 & 31.4 \\
\hline South Western Cape, whites (10) & 1988 & 25 to 64 & 17.6 & 20.4 \\
\hline Durban, Indians (21) & 1990 & 25 to 69 & 3.5 & 17.6 \\
\hline Demographic \& Health Survey, African & 1998 & 15 & 7.7 & 30.5 \\
\hline Demographic \& Health Survey, Mixed & 1998 & 15 & 9.1 & 28.3 \\
\hline Demographic \& Health Survey, Asian & 1998 & 15 & 8.7 & 20.2 \\
\hline Demographic \& Health Survey, white & 1998 & 15 & 19.8 & 24.3 \\
\hline
\end{tabular}

terventions, which are culturally sensitive for particular target groups. Policies should be directed toward raising the educational status of women, because they are key figures in improving the nutritional status of the whole nation. The most challenging aspects of obesity-management in South Africa relates to the perceptions of the African community regarding the positive values ascribed to obesity.

\section{Acknowledgments}

The authors wish to acknowledge the South African National Department of Health as the initiator and main funder of this work, the Medical Research Council as cocoordinator and funder, and the Center for Health Systems Research and Development and their teams for the fieldwork, Macro International for technical assistance, and United States Agency for International Development for additional funding. In addition, the provincial Departments of Health are acknowledged for providing a provincial co-coordinator to assist with facilitating the survey and the Human Sciences Research Council for monitoring the fieldwork quality. Statistics South Africa provided the sampling frame and sample details for which they are thanked, as are all the participants. The authors performed this work for the South African Demographic and Health Coordinating Team.

\section{References}

1. Omran AR. The epidemiologic transition theory: a preliminary update. J Trop Pediatr. 1983;29:305-16.
2. Popkin BM, Doak CM. The obesity epidemic is a worldwide phenomenon. Nutr Rev. 1998;56:106-14.

3. World Health Organization. Obesity: preventing and managing the Global Epidemic. Report of a WHO Consultation on Obesity. Geneva, Switzerland: World Health Organization; 1998.

4. Reddy P, Steyn K, Saloojee Y. The emerging epidemic of cardiovascular disease in developing countries. Circulation. 1998;97:596-601.

5. Dyer AR, Elliot $\mathbf{P}$. The INTERSALT study: relations of body mass index to blood pressure. INTERSALT Co-operative Research Group. J Hum Hypertens. 1989;3:229-308.

6. Steyn K, Fourie JM, Rossouw JE, Langenhoven ML, Joubert G, Chalton DO. Anthropometric profile of the Coloured population of the Cape Peninsula. The CRISIC study. $S$ Afr Med J. 1990;78:68-72.

7. Lackland DT, Orchard TJ, Keil JE, et al. Are race differences in the prevalence of hypertension explained by body mass and fat distribution? A survey in a biracial population. Int J Epidemiol. 1992;21:236-45.

8. Hubert HB, Feinleib M, McNamara PM, Castelli WP. Obesity as an independent risk factor for cardiovascular disease: a 26-year follow-up of participants in the Framingham Heart Study. Circulation. 1983;67:968-77.

9. Feinleib M. Epidemiology of obesity in relation to health hazards. Ann Intern Med. 1985;103:1019-24.

10. Jooste PL, Steenkamp HJ, Benadé AJS, Rossouw JE. Prevalence of overweight and obesity and its relation to coronary heart disease in the CORIS study. S Afr Med J. 1988;74: 101-4. 
11. Pi-Sunyer FX. Obesity and diabetes in blacks. Diabetes Care. 1990;13:1144-9.

12. West KM. Diabetes in American Indians. Adv Metab Dis. 1978;9:29-48.

13. Garfinkel L. Overweight and cancer. Ann Intern Med. 1985; 103:1034-6.

14. National Institutes of Health Consensus Panel. Health implications of obesity. National Institutes of Health Consensus Development Conference Statement. Ann Intern Med. 1985;103:1073-7.

15. Steyn K, Bourne L, Jooste P, Fourie JM, Rossouw K, Lombard C. Anthropometric profile of a black population of the Cape Peninsula in South Africa. East Afr Med J. 1998;75:35-40.

16. Vorster HH, Wissing MP, Venter CS, et al. The impact of urbanisation of physical, physiological and mental health of African in the North West Province of South Africa: the THUSA study. S Afr J Science. 2000;96:505-13.

17. Mollentze WF, Moore A, Joubert G, et al. Cardiovascular risk factors in the black population of QwaQwa. S Afr J Clin Nutr. 1993;6:50-1.

18. Bourne L, Steyn K. Rural/urban nutrition-related differentials among adult ethnic groups in South Africa, with special emphasis on the black population. S Afr J Clin Nutr. 2000;13:S23-8.

19. Statistics South Africa. Report of the Census Evaluation Task Team of the Statistics Council on the Final Post-Enumeration Survey adjusted Count of the 1996 Population Census. 1996; http://www.statssa.gov.za/default2.asp (Accessed May 9, 2002)

20. Doll R, Smith PG. Comparison between registries: age-standardized rates. In: J Waterhouse, C Muir, K Shanmugaratnam, J Powell, eds. Cancer Incidence in Five Continents, Vol. IV. Lyon, France: International Agency for Research on Cancer; 1982, pp. 671-4.

21. Seedat YK, Mayet FGH, Khan S, Somers SR, Joubert G. Risk factors for coronary heart disease in the Indians of Durban. S Afr Med J. 1990;78:447-54.

22. Steyn K, Fourie JM, Lombard CJ, Katzenellenbogen J, Bourne LT, Jooste PL. Hypertension in the black community of the Cape Peninsula. The BRISK study. East Afr Med J. 1996;73:756-60.

23. Levitt NS, Katzenellenbogen JM, Hoffman MN, Bonnici F. The prevalence and identification of risk factors for NIDDM in urban Africans in Cape Town, South Africa. Diabetes Care. 1993;16:601-6.
24. Mvo Z, Dick J, Steyn K. Perceptions of overweight African women about acceptable body size of women and children. Curationis. 1999;22:27-31.

25. Clark RA, Niccolai L, Kissinger PJ, Peterson Y, Bouvier V. Ethnic differences in body image attitudes and perceptions among women infected with human immunodeficiency virus. J Am Diet Assoc. 1999;99:735-7.

26. Dawson DA. Ethnic differences in female overweight: data from the 1985 National Health Interview Survey. Am J Public Health 1988;78:1326-9.

27. Fox FW. Diet in the urban locations as indicated by the survey. In: M Janisch, ed. A Study of African Income and Expenditure in 987 Families in Johannesburg. Johannesburg, South Africa: City of Johannesburg, Department of NonEuropean and Native Affairs; 1940.

28. Bourne LT. Dietary Intake in an Urban African Population in South Africa-With Special Reference to the Nutrition Transition. Cape Town, South Africa: University of Cape Town; 1996. Thesis.

29. Jeffery RW, French SA. Epidemic obesity in the United States: are fast foods and television viewing contributing? Am J Public Health. 1998;88:277-80.

30. Sundquist J, Johansson SE. The influence of socioeconomic status, ethnicity and lifestyle on body mass index in a longitudinal study. Int J Epidemiol. 1998;27:57-63.

31. Donahue RP, Abbott RD, Bloom E, Reed DM, Yano K. Central obesity and coronary heart disease in men. Lancet. 1987;1:821-4.

32. Hodge AM, Dowse GK, Gareeboo H, Tuomilehto J, Alberti KG, Zimmet PZ. Incidence, increasing prevalence, and predictors of change in obesity and fat distribution over 5 years in the rapidly developing population of Mauritius. Int $J$ Obes Relat Metab Disord. 1996; 20:137-46.

33. Flegal KM, Carroll MD, Kuczmarski RJ, Johnson CL. Overweight and obesity in the United States: prevalence and trends, 1960-1994. Int J Obes Relat Metab Disord. 1998;22: 39-47.

34. Berrios X, Koponen T, Huiguang T, Khaltaev N, Puska P, Nissinen A. Distribution and prevalence of major risk factors of noncommunicable diseases in selected countries: the WHO Inter-Health Programme. Bull World Health Organ. 1997;75: 99-108. 